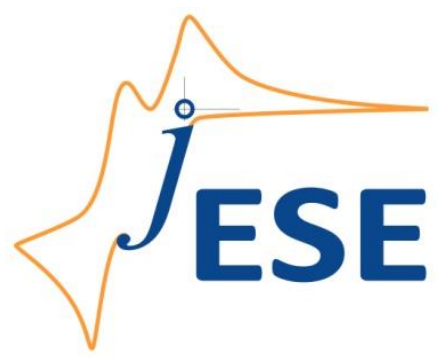

Open Access : : ISSN 1847-9286

www.jESE-online.org

Original scientific paper

\title{
Voltammetric studies on mercury behavior in different aqueous solutions for further development of a warning system designed for environmental monitoring
}

Paul-Cristinel Verestiuc, Igor Cretescu* ${ }^{*}$, Oana-Maria Tucaliuc, Iuliana-Gabriela Breaban and Gheorghe Nemtoi**

Faculty of Geography and Geology, Al. I. Cuza University of Iasi, 20 A. Carol I Bd., Iasi, 700505, Romania

*Faculty of Chemical Engineering and Environmental Protection, Gheorghe Asachi Technical University of Iasi, 73, D. Mangeron Street, Iasi, 700050, Romania

**Faculty of Chemistry, Al. I. Cuza University of Iasi, 11, Carol I Bd., Iasi, 700506, Romania

Corresponding author: E-mail: icre@tuiasi.ro; Tel.: +40-741-914-342.

Received: October 5, 2014; Revised: October 31, 2014; Published: December 6, 2014

\begin{abstract}
This article presents some results concerning the electrochemical detection of mercury in different aqueous solutions, using the following electrodes: platinum-disk electrode $(P D E)$, carbon paste electrode (CPE) and glass carbon electrode (GCE). Using the voltammetric technique applied on the above mentioned electrodes, the experimental conditions were established in order to obtain the maximum current peaks, in terms of the best analytical characteristics for mercury analyses. The dependence equations of cathodic current intensity on the scan rate were established in the case of mercury ion discharge in each prepared solution of $0.984 \mathrm{mM} \mathrm{HgCl}_{2}$ in different electrolyte background: $0.1 \mathrm{M} \mathrm{KCl}, 0.1 \mathrm{M} \mathrm{H}_{2} \mathrm{SO}_{4}$ and $0.9 \% \mathrm{NaCl}$. Among the three investigated electrodes, the carbon paste electrode presented the highest detection sensitivity toward mercury ions in the aqueous solution. It was observed that, at a low scanning rate, the $\mathrm{pH}$ had an insignificant influence over the current peak intensity; however, the quantification of this influence was achieved using a quadratic polynomial equation, which could prevent the errors in mercury detection in case of industrial waste stream $\mathrm{pH}$ changes. The calibration curves for mercury in $0.9 \% \mathrm{NaCl}$ solution and in the tap water respectively were carried out.
\end{abstract}

\section{Keywords}

Cathodic linear voltammetry; platinum electrode; carbon paste electrode; glass carbon electrode; mercuric ion; flow electrochemical cell. 


\section{Introduction}

The ubiquitous presence of mercury in the environment is due to both natural geological activities as well as due to increasing anthropogenic pollution. Because of its unique electronic configuration, mercury behaves similarly to noble gas elements, but the physical and chemical properties of mercury such as high surface tension, high specific gravity, low electrical resistance, and a constant volume of expansion over the entire temperature range in liquid state can rapidly transform this element into a hazardous air pollutant [1,2].

The Water Framework Directive (2000/60/EC) classified mercury as a priority hazardous substance, establishing that from 2015, no more mercury from production processes can be discharged [3, 4].

Mercury exists in a large number of forms, i.e. as "elemental" $\mathrm{Hg}(0)$, monovalent or divalent mercury $\mathrm{Hg}(\mathrm{I})$ and $\mathrm{Hg}(\mathrm{II})$, and in inorganic and organic compounds. Metallic mercury $\mathrm{Hg}(0)$ and most mercury compounds present high toxicity, acting as a bioaccumulative neurotoxin $[5,6]$.

Mercury ions are strongly adsorbed by soils or sediments in acid medium and are slowly desorbed, due to the content of clay minerals and/or organic matter, which are responsible for its behavior. The reaction products resulting from the methylation of inorganic mercury forms impose a significant risk to humans and wildlife due to tendency to accumulate in the food chain, and their ability to act as neurotoxins [6,7]. Exposure to various forms of mercury will harm human health. Moderate and repeated exposure to organic forms (lower than a few $\mathrm{mg} \mathrm{m}^{-3} \mathrm{Hg}$, but higher than $0.05 \mathrm{mg} \mathrm{m}^{-3} \mathrm{Hg}$ ) causes symptoms of poisoning such as: lack of coordination of movement, impairment of peripheral vision, speech, hearing or walking as well as muscle weakness. Inhaled or physical contact with inorganic forms cause: tremors, emotional or neuromuscular changes, insomnia, headaches, disturbances in sensation, changes in nerve responses, and performance deficits on tests of cognitive function. With prolonged or high concentration exposure, kidney effects, respiratory failure and death may occur $[8,9]$.

Mercuric chloride $\left(\mathrm{HgCl}_{2}\right)$ is used as a depolarizer in electric batteries and as a reactant in organic synthesis and analytical chemistry [10]. The presence of this element in different environmental components could be considered as harmful to human health well environmentally dangerous due to the mercury content.

Taking into consideration all the above mentioned aspects, the detection of mercuric ion has become a priority for environmental safety and human health. The determination of trace amounts of mercury, has led to some analytical problems because it can be found in several chemical forms [11]. For an accurate determination of mercury at trace and ultra-trace levels, analytical methods with high sensitivity and selectivity are needed. There are a number of analytical methods for mercury detection which require expensive instruments, well-controlled experimental conditions, sample preparation and relatively large sample volumes [12]. Electrochemical detection of trace metals offers important advantages, such as remarkable sensitivity, inherent miniaturization and portability, remote monitoring and decentralized measurements, low cost and compatibility with turbid samples $[13,14]$. Therefore, electrochemical methods are less costly and require no sophisticated equipment.

Chemically modified electrodes have received increasing attention, which has led to improvements in the sensitivity and selectivity of electrochemical analysis techniques in the recent decades. The determination of $\mathrm{Hg}(\mathrm{II})$ ions using chemically modified electrodes has been investigated recently, using plants [14], gold film [15], polymer films [16] or organic compounds with chelating groups [17]. 
The behavior of electrodes has also been studied using modified a carbon paste electrode [18], modified glass carbon electrode [17] or modified gold nanoelectrode ensembles [19].

A relatively recent review of electrochemical sensors and detectors has been done by Bakker [20], characterizing this area of research as being one of the most fruitful and interdisciplinary areas of research in analytical chemistry. A recent paper by Pujol [21] analyzed the actual state of art concerning the sensors and devices for heavy metals detection in water, but the mercury detection from environmental samples was not studied in details.

For this reason in this study it was investigated the cathodic discharge of the mercuric ion on different type of electrodes such as: platinum-disk electrode, carbon paste electrode and glass carbon electrode, in respectively different aqueous solutions $\left(0.1 \mathrm{M} \mathrm{KCl}, 0.1 \mathrm{M} \mathrm{H}_{2} \mathrm{SO}_{4}, 0.9 \% \mathrm{NaCl}\right.$ ) by the voltammetric method in order to find the most suitable conditions for analytical purpose.

\section{EXPERIMENTAL}

In order to simulate the wastewater from the industrial stream, aqueous solutions of $\mathrm{HgCl}_{2}$ in $0.1 \mathrm{M} \mathrm{H}_{2} \mathrm{SO}_{4}$ at a $\mathrm{pH}$ value of $0.99,0.9 \% \mathrm{NaCl}$ at a $\mathrm{pH}$ value of 5.66 and $0.1 \mathrm{M} \mathrm{KCl}$ at a $\mathrm{pH}$ value of 7.43 was prepared, using analytical purity reagents and double distilled water. The investigation of mercury behavior in these solutions was carried out using voltammetric measurements [22-26] with the above mentioned electrodes (GCE, CPE and PDE) individually. These electrodes play the role of working electrode (WE) in a flow electrochemical cell (as is presented in Fig. 1) through which the samples from the industrial stream are passed using a peristaltic pump. A saturated calomel electrode (SCE) was used as the reference electrode (RE), while a platinum electrode was used as the counter (auxiliary) electrode (CE) at the temperature of $25^{\circ} \mathrm{C}$. Also, $\mathrm{pH}$ and temperature sensors were located in the electrochemical cell in order to provide corrections in the case of possible changes in the above mentioned parameters which should be kept constant at the same values as were used during the calibration procedure.

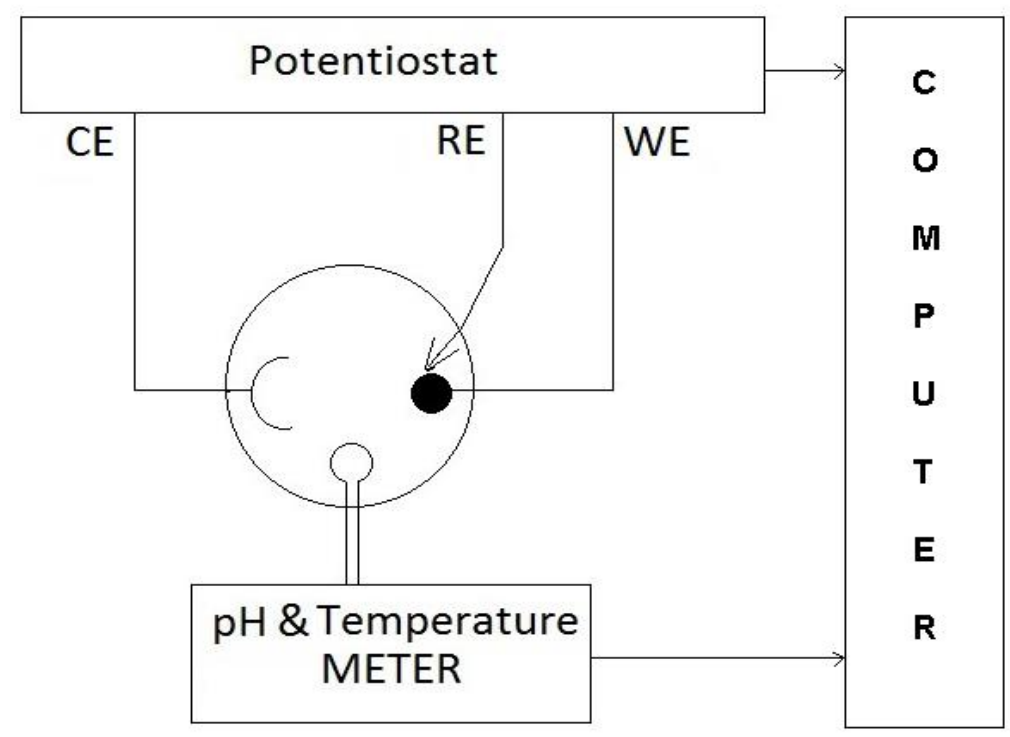

Figure 1. Experimental setup for study of the voltammetric detection of mercury in aqueous solution

The $\mathrm{pH}$ corrections were achieved using software (the $\mathrm{pH}$ dependence of the current peak was determined by a simple equation), while the temperature corrections were first achieved by the thermostatic system for sample processing and finally by the software corrections for the fine $\mathrm{pH}$ adjustments. 
The voltammograms were recorded using the potentiostat VoltaLab 32 (Radiometer Analytical) [27-29] after stopping the flow of liquid samples through the electrochemical cell (using a solenoid mini-valve) and nitrogen bubbling in the investigated solutions, in order to remove the dissolved oxygen.

The investigated electrodes were used as purchased from Radiometer Analytical, except for the carbon paste electrode, which was prepared according to methods previously presented in the literature [30-31]. The electrode surfaces were: $3.14 \cdot 10^{-2} \mathrm{~cm}^{2}$ for PDE; $7.0710^{-2} \mathrm{~cm}^{2}$ for GCE and $19.6310^{-2} \mathrm{~cm}^{2}$ for CPE.

\section{Results and discussion}

In Figures 2, 3 and 4, the cathodic linear voltammograms are presented, corresponding to the reduction of $\mathrm{Hg}^{2+}$ on the $\mathrm{PDE}(\Phi=2 \mathrm{~mm})$ at different scanning rates in different aqueous media.

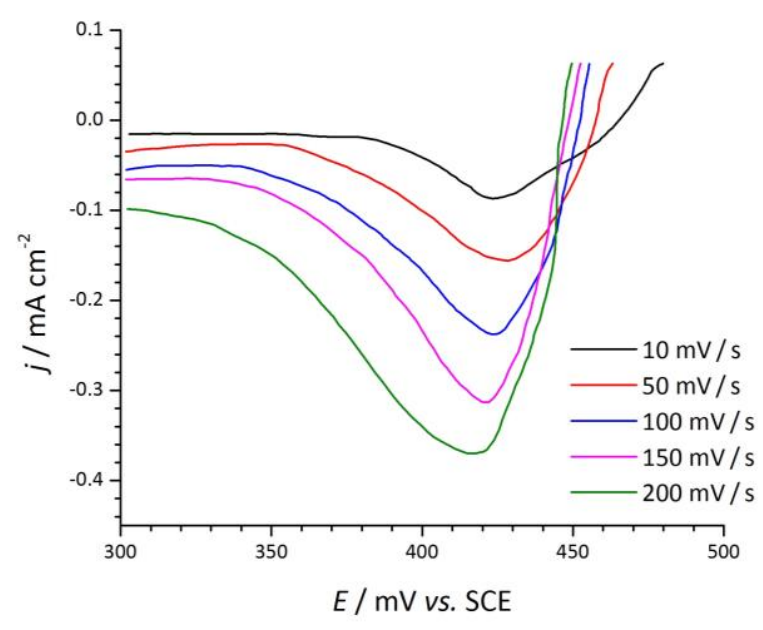

Figure 2. Linear cathodic voltammograms on $\mathrm{PDE}$ in $0.1 \mathrm{M} \mathrm{H}_{2} \mathrm{SO}_{4}$ aqueous solution recorded at different scanning rates

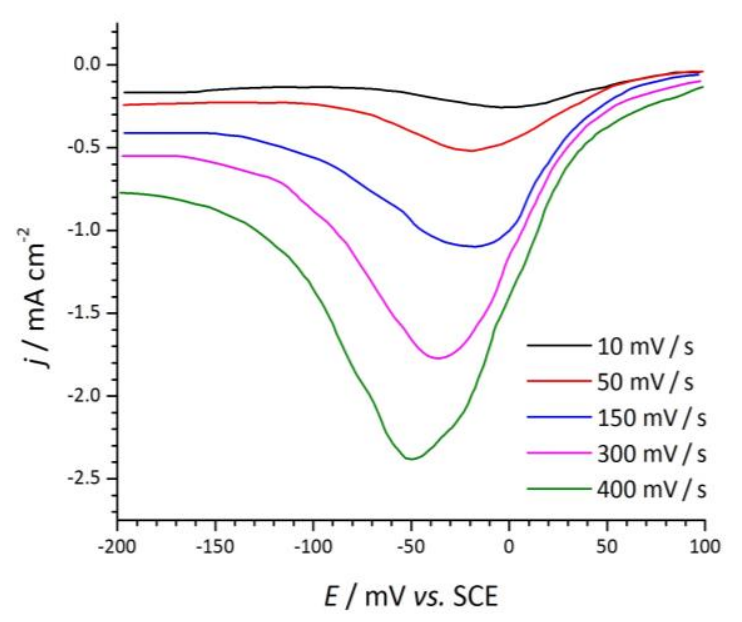

Figure 4. Linear cathodic voltammograms on PDE in $0.9 \% \mathrm{NaCl}$ aqueous solution recorded at different scanning rates.

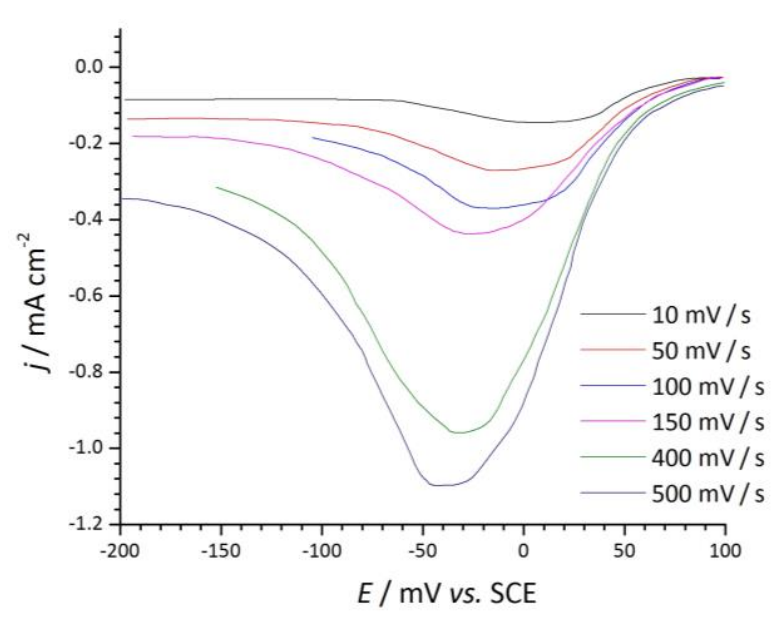

Figure 3. Linear cathodic voltammograms on PDE in $0.1 \mathrm{M} \mathrm{KCl}$ aqueous solution recorded at different scanning rates

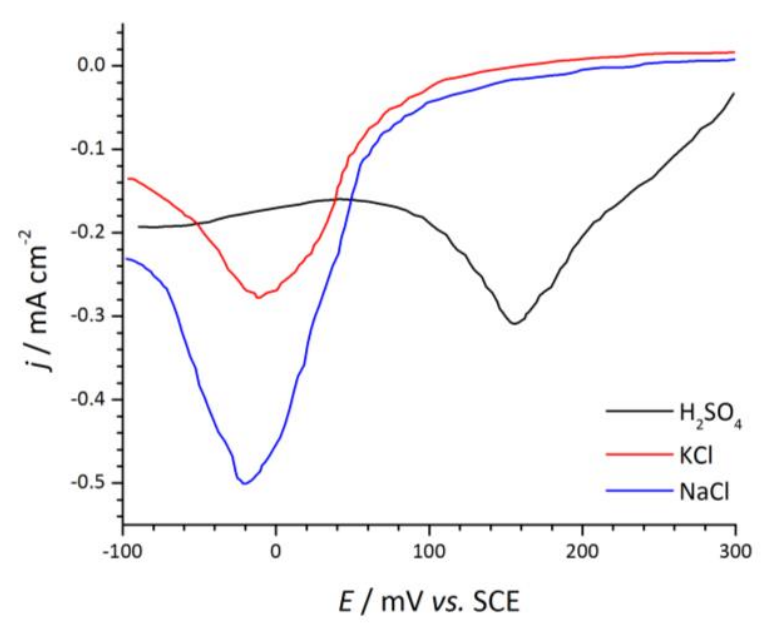

Figure 5. Linear cathodic voltammograms of mercury ion discharge on PDE in different solutions at constant scanning rate of $50 \mathrm{mV} \mathrm{s}^{-1}$ 
Concerning the electrochemical behavior of mercuric ions in the three different aqueous solutions shown in Figures 2-4, it was observed that there was a simultaneous increase in PDE sensitivity with the scanning rate, at a concentration of $0.984 \mathrm{mM}$, as was expected.

This behavior leads to the following dependence equations for the cathodic peaks, which express the discharge of the mercuric ion on the platinum electrode, in all investigated solutions:

a. $0.1 \mathrm{M} \mathrm{H}_{2} \mathrm{SO}_{4}: I=-2.114-0.058 v+3.474 \times 10^{-5} v^{2}(R=0.99952)$

b. $0.1 \mathrm{M} \mathrm{KCl}: l=-4.285-0.072 \mathrm{v}+2.168 \times 10^{-5} v^{2}(R=0.99757)$

c. physiological serum $(0.9 \% \mathrm{NaCl}): I=-6.815-0.140 v-6.611 \times 10^{-5} v^{2}(R=0.99827)$

where: $I=$ intensity current $(\mathrm{mA}), v=$ scanning rate $\left(\mathrm{mV} \mathrm{s}^{-1}\right), R=$ correlation coefficient

According to the experimental results, it was noted that the highest sensitivity of PDE was obtained in physiological serum, followed by the solution prepared based on sulfuric acid and potassium chloride, respectively (Figure 5).

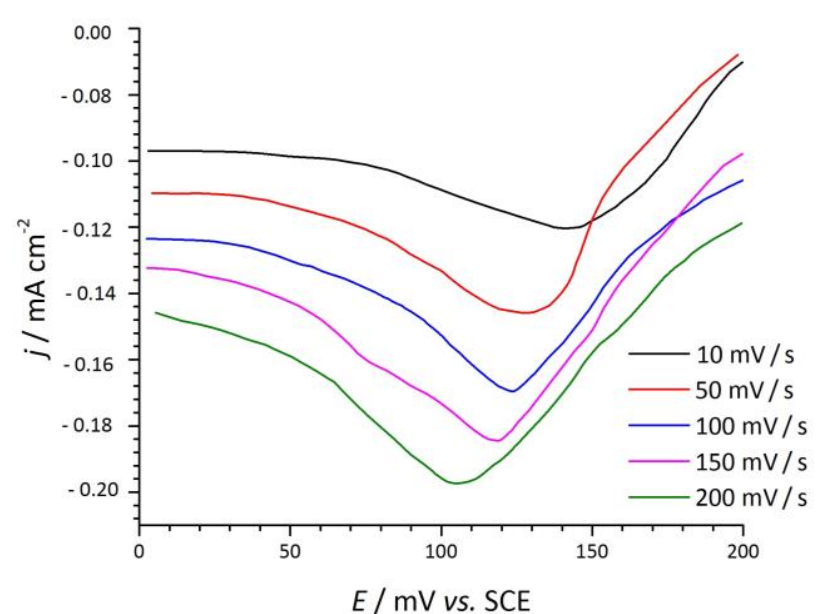

Figure 6. Linear cathodic voltammograms on CGE in $0.1 \mathrm{M} \mathrm{H}_{2} \mathrm{SO}_{4}$ aqueous solution recorded at different scanning rates.

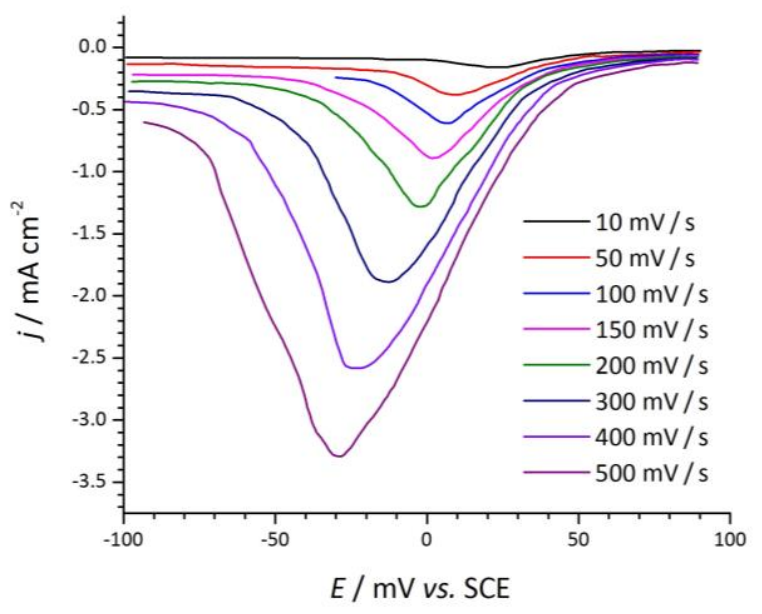

Figure 8. Linear cathodic voltammograms on CGE in $0.9 \% \mathrm{NaCl}$ aqueous solution recorded at different scanning rates

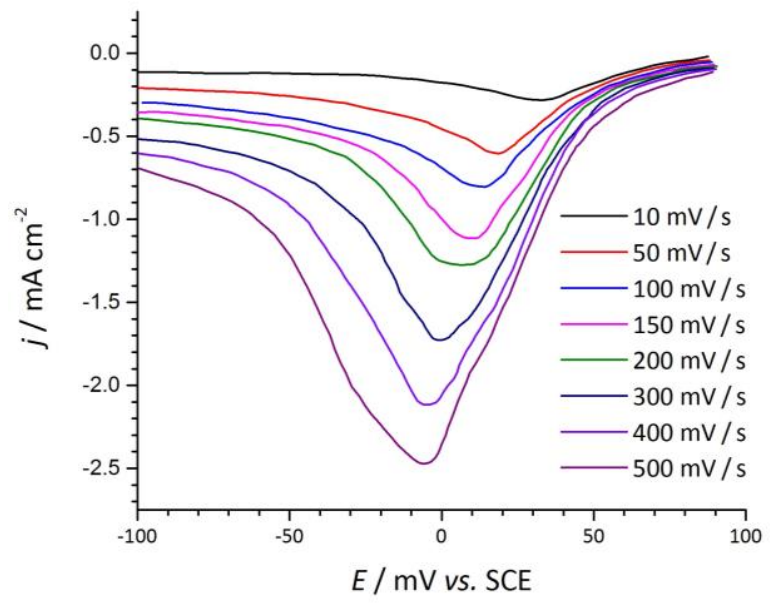

Figure 7. Linear cathodic voltammograms on CGE in $0.1 \mathrm{M} \mathrm{KCl}$ aqueous solution recorded at different scanning rates

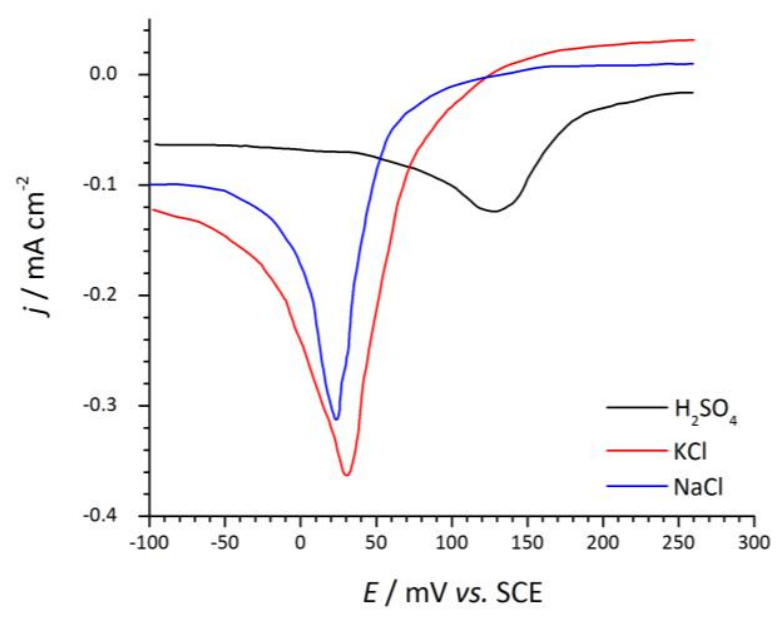

Figure 9. Linear cathodic voltammograms of mercury ion discharge on GCE in different aqueous solution at constant scanning rate of $50 \mathrm{mV} / \mathrm{s}$ 
Figures 6-8 present the cathodic linear voltammograms for each of the aqueous solutions recorded on the GCE at different scanning rates.

In this case, the following dependence equations for the cathodic peak were established, which express the discharge of the mercuric ion $(0.984 \mathrm{mM})$ on the platinum disc electrode, in all three investigated solutions:

a. $0.1 \mathrm{M} \mathrm{H}_{2} \mathrm{SO}_{4}$ : I = -5.7573-0.06488+1.3139 $\times 10^{-4} \mathrm{v}^{2}(R=0.99404)$

b. $0.1 \mathrm{M} \mathrm{KCl}: l=-11.895-0.239 v+1.079 \times 10^{-4} v^{2}(R=0.998)$

c. physiological serum $(0.9 \% \mathrm{NaCl}): I=-3.745-0.347 v+1.355 \times 10^{-4} \mathrm{v}^{2}(\mathrm{R}=0.99918)$

where: $I=$ current intensity $(\mathrm{mA}), v=$ scanning rate $\left(\mathrm{mV} \mathrm{s}^{-1}\right), R=$ correlation coefficient

In accordance with the Figure 9, the sensitivity of the GCE toward the mercuric ion was highest in $\mathrm{KCl}$ aqueous solution and lowest in sulfuric acid.

The entire cathodic process of mercuric ion discharge on the CPE in all of the three investigated solutions is presented in detail in linear voltammograms (Figures 10-12).

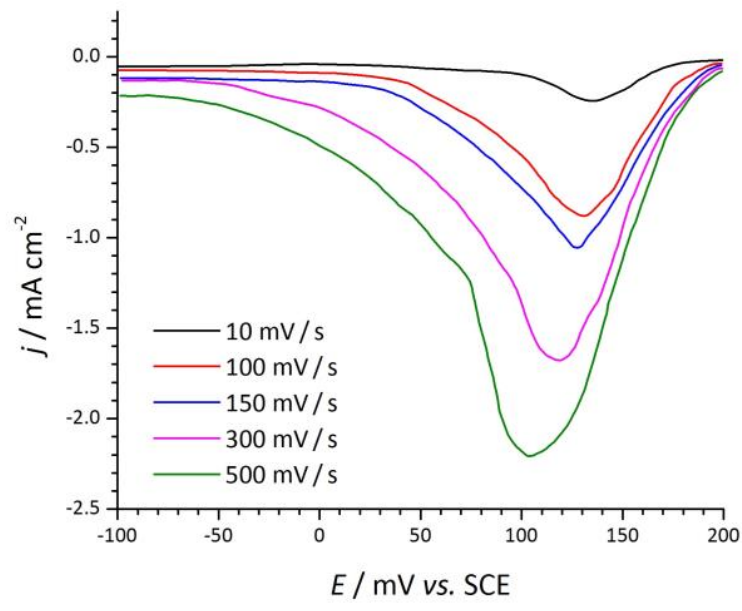

Figure 10. Linear cathodic voltammograms on $\mathrm{CPE}$ in $0.1 \mathrm{M} \mathrm{H}_{2} \mathrm{SO}_{4}$ aqueous solution recorded at different scanning rates.

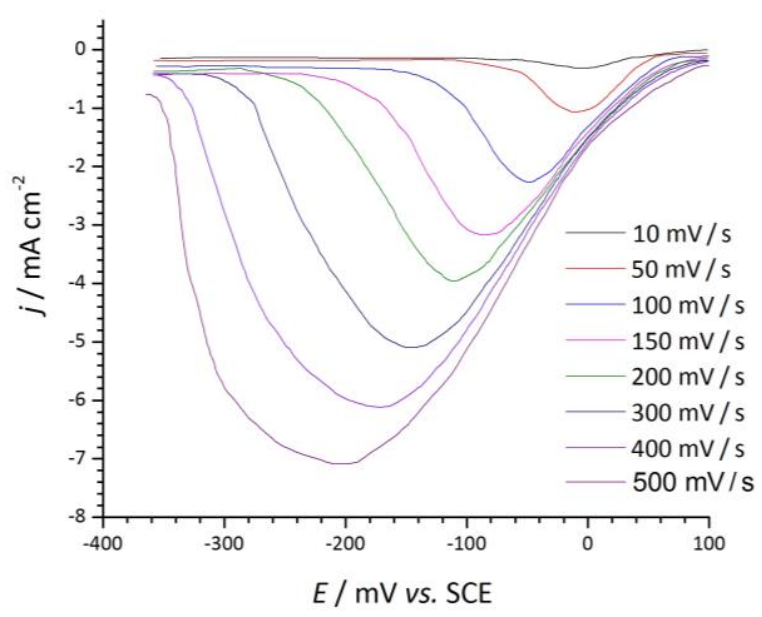

Figure 12. Linear cathodic voltammograms on CPE in $0.9 \% \mathrm{NaCl}$ aqueous solution recorded at different scanning rates

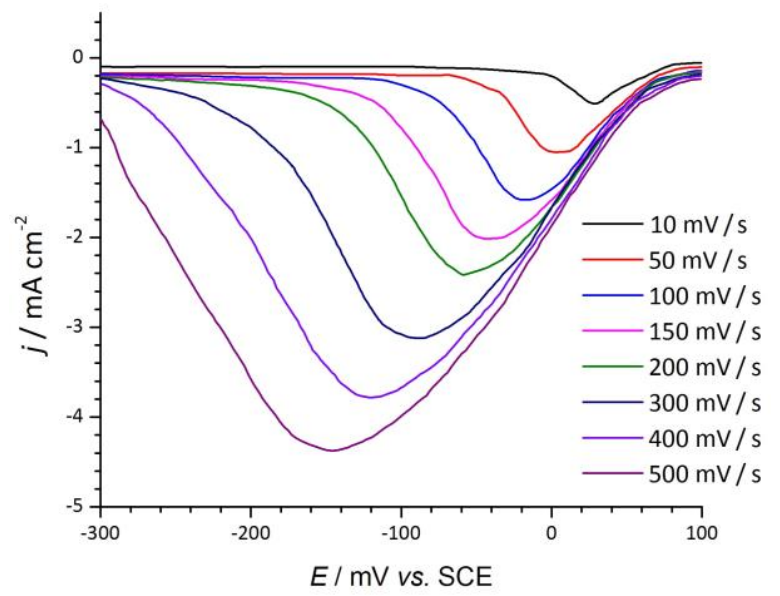

Figure 11. Linear cathodic voltammograms on CPE in $0.1 \mathrm{M} \mathrm{KCl}$ aqueous solution recorded at different scanning rates

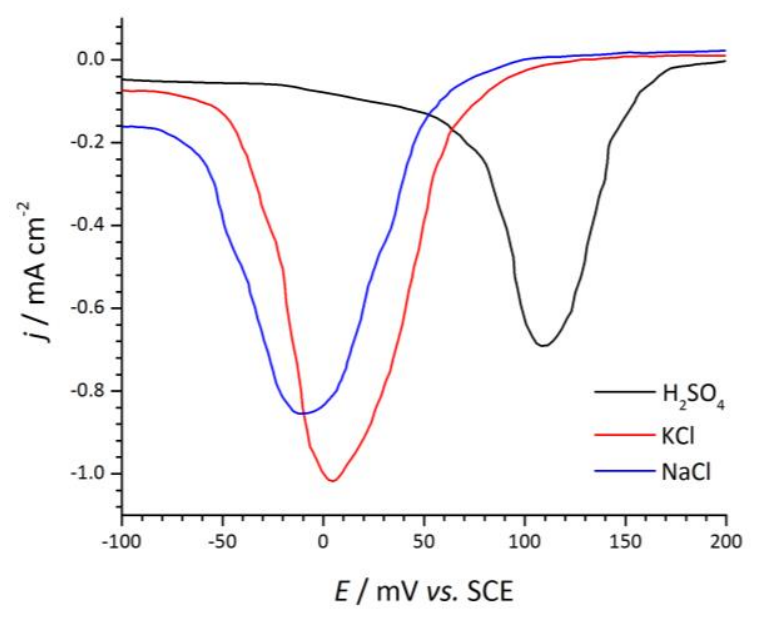

Figure 13. Linear cathodic voltammograms of mercury ion discharge on CPE in different solutions at constant scanning rate of $50 \mathrm{~m} \mathrm{~V} \mathrm{~s}^{-1}$ 
Data obtained using the CPE revealed the same behavior as with the GCE regarding higher sensitivity, as follows: $0.1 \mathrm{M} \mathrm{KCl}$, physiological serum and $0.1 \mathrm{M} \mathrm{H}_{2} \mathrm{SO}_{4}$ (Figure 13).

The measurements performed on the $\mathrm{CPE}$, in each investigated solution led to the following equations:

a. $0.1 \mathrm{M} \mathrm{H}_{2} \mathrm{SO}_{4}$ : $I=-38.137-1.282 v+9.944 \times 10^{-4} v^{2}(R=0.99581)$

b. $0.1 \mathrm{M} \mathrm{KCl}: I=-80.923-2.168 v+1.27 \times 10^{-3} v^{2}(R=0.99808)$

c. physiological serum $(0.9 \% \mathrm{NaCl}): I=-34.086-3.25 v+2.23 \times 10^{-3} v^{2}(R=0.99867)$

where: $I=$ current intensity $(\mathrm{mA}), v=$ scanning rate $\left(\mathrm{mV} \mathrm{s}^{-1}\right), R=$ correlation coefficient

These equations point out the dependence of the current intensity (corresponding to the discharge of mercuric ions in aqueous solutions at a concentration of $0.984 \mathrm{mM} \mathrm{HgCl}_{2}$ ) on scanning rates.

Increasing the scanning rate during investigations into mercuric ion discharge for each studied electrode in the aqueous solutions led to a change in the cathodic potential values, which were shifted to negative values, suggesting a quasi-reversible process.

Among the electrodes used in this study, the carbon paste electrode was the most sensitive with respect to the cathodic discharge of mercuric ions in all the investigated aqueous solutions. Taking into consideration this aspect, the $\mathrm{pH}$ dependence of the current peak (Figure 14) and the calibration curves (Figure 15) in the $\mathrm{NaCl}$ solution and tap water, respectively, were presented only for the CPE.

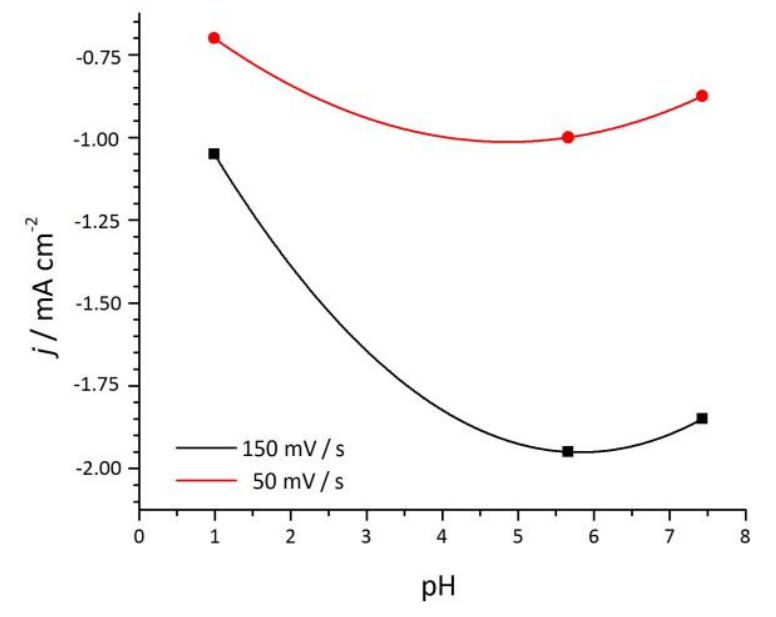

Figure 14. Influence of solution $\mathrm{pH}$ on the cathodic peak on CPE in $0.9 \% \mathrm{NaCl}$ aqueous solution recorded at two scanning rates

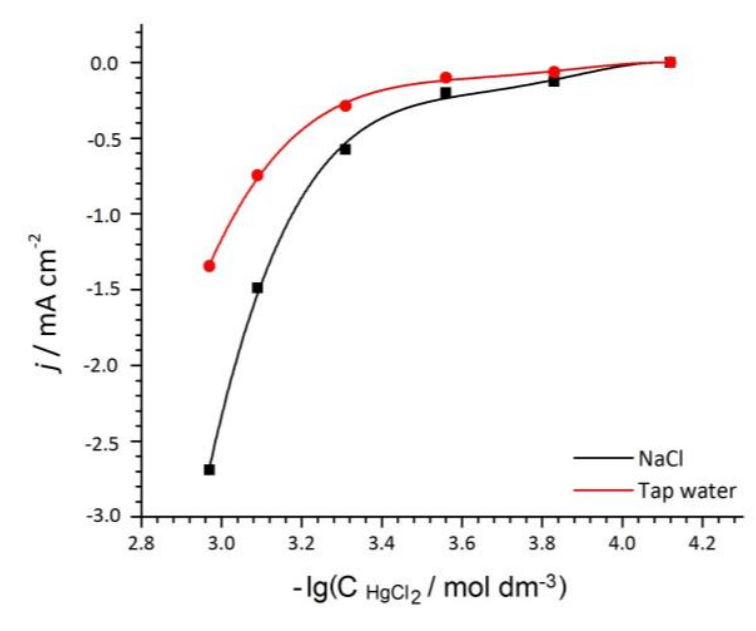

Figure 15. Calibration curves for determination of $\mathrm{HgCl}_{2}$ using $\mathrm{CPE}$ in $0.9 \% \mathrm{NaCl}$ aqueous solution and tap water, respectively

As presented in Figure 14, a low $\mathrm{pH}$ dependence of the current peak was observed for a scanning rate of $50 \mathrm{mV} \mathrm{s}^{-1}$, but if this value was multiplied by three fold, the dependence became more evident, especially in the acidic region. These equations are presented as follows:

$$
\begin{aligned}
& I_{50}=-0.12847-0.09001 \mathrm{pH}+0.00774 \mathrm{pH}^{2} \\
& I_{150}=-0.10381-0.0407 \mathrm{pH}+0.00419 \mathrm{pH}^{2}
\end{aligned}
$$


The calibration curves presented in Figure 15 pointed out an approximately linear dependence for both calibration curves, which are separated into two regions. However, these calibration curves could be very well fitted following quadratic polynomial equations:

$$
\begin{aligned}
& X=-\lg \left[\mathrm{HgCl}_{2}\right] \\
& I_{\mathrm{NaCl}}=-242.414+257.620 X-102.678 X^{2}+18.175 X^{3}-1.205 X^{4} \\
& I_{\text {tap water }}=-121.207+128.825 X-51.339 X^{2}+9.087 X^{3}-0.602 X^{4}
\end{aligned}
$$

The decreased sensitivity of the voltammetric method for mercury detection in real samples (tap water provided from the lasi drinking water treatment plant) was evident, but the analytical signal was sufficiently high to be discriminated from the global noise determined in such a complex matrix.

The response limit of the concentration peak for $\mathrm{Hg}$ (II) detection was in the range of $10^{-5} \mathrm{M}$ to $10^{-3} \mathrm{M}$. The optimal operating conditions were established after a period of three minutes of preconcentration.

\section{Conclusions}

The following conclusions can be drawn for the voltammetric studies regarding the behavior of mercuric ions in the presence of different supporting electrolytes in aqueous solutions using different electrodes:

- The cathodic discharge of mercury ions from $\mathrm{HgCl}_{2}$ aqueous solutions in different electrolyte support media such as $0.1 \mathrm{M} \mathrm{KCl}$, physiological serum $(0.9 \% \mathrm{NaCl})$, and $0.1 \mathrm{M} \mathrm{H}_{2} \mathrm{SO}_{4}$, using different electrode materials (platinum, glass carbon and carbon paste) was evidenced by a relevant current peak, whose height (in terms of the analytical method sensitivity) is dependent on the potential scanning rate;

- The cathodic discharge of mercuric ions, in all investigated aqueous solutions, was a slow and quasi-reversible process, on all three of the investigated electrode materials;

- The best electrode was the carbon paste electrode, in terms of the sensitivity toward mercuric ions, in concordance with the equations describing the dependence between the cathodic peak intensity and the potential scanning rate. It was pointed out that the CPE presented the highest detection sensitivity toward mercuric ions in an aqueous solution, working in a wide $\mathrm{pH}$ range and having a short response time. Besides these aspects, the CPE is very easily prepared and has good reproducibility and repeatability for mercury analysis, which recommend it for this analytical application;

- Based on the results, a miniaturized voltammetric flow cell will be developed as an integrated component of the equipment used for mercury detection/monitoring in industrial waste streams. Based on the mercury detection capacity, a warning system will be designed to avoid mercury discharge into surface waters in the case of accidentally increasing the mercury concentration.

- Due to the increased capacity for mercury detection by this proposed monitoring system, based on a voltammetric method and an electrochemical flow cell, its versatility could be extended using some auxiliary equipment to other environmental components such as air and soil.

- At low scanning rate, the $\mathrm{pH}$ had an insignificant influence over the current peak intensity in the case of the CPE in $0.9 \% \mathrm{NaCl}$ solution. 
- In order to avoid errors in mercury detection in cases of industrial stream pH changes, the quantification of the $\mathrm{pH}$ influence was achieved using a quadratic polynomial equation.

- The calibration curves for mercury in a $0.9 \% \mathrm{NaCl}$ solution and in tap water had similar shapes (which could be divided into two linear sections) but with decreased the sensitivity in tap water.

Acknowledgements: This work was supported by the strategic grant POSDRU/159/1.5/S/133652, co-financed by the European Social Fund within the Sectorial Operational Program Human Resources Development 2007-2013.

\section{References}

[1] R. P. Mason, W. F. Fitzgerald, F. M. M. Morel, Geochimica et Cosmochimica Acta 58 (15) (1994) 3191-3198

[2] W. H. Schroeder, J. Munthe, Atmospheric Environment 32 (5) (1998) 809-822

[3] A. Pichard, Mercury and its derivates, Institut National de L'environment Industiel et des Risques, Amiens, France, 2000, p. 6-8

[4] J. De Clerq, International Journal of Industry Chemistry 3 (1) (2012)

[5] O. Lindquist, K. Johansson, M. Aastrup, A. Andersson, L. Bringmark, G. Hovsenius, L. Hakanson, A. Iverfeldt, M. Meili, B. Timm, Water, Air, \& Soil Pollution 55 (1) (1991) 23-32

[6] H. Satoh, Industrial Health 38 (1) (2000) 153-164

[7] W. F. Fitzgerald, T.W. Clarkson, Environmental Health Perspectives 96 (1) (1991) 159-166

[8] U. S. Environmental Protection Agency, Mercury Study Report to Congress, Volume III, 1997, p. 93

[9] T. W. Clarkson, L. Magos, G. J. Myers, The New England Journal of Medicine 349 (18) (2003) 1731-1737

[10] W. T. S Zaugg, D. Foreman, L. M. Faires, M. G. Werner, T. J. Leiker; P. F. Rogerson, Environmental Science \& Technology 26 (7) (1992) 1307-1314

[11] D. W. Boeing, Chemosphere 40 (1) (2000) 1335 - 1351

[12] O. M. Tucaliuc, I. Cretescu, G. Nemtoi , I. G. Breaban, G. Soreanu, O. G. Iancu, Environmental Engineering and Management Journal 13 (8) (2014) 2051-2061

[13] J. Wang, B. Tian, J. Wang J. Lu, C. Olsen, C. Yarnitzky, K. Olsen, D. Hammerstrom, W. Bennet, Analytica Chimica Acta 385 (1) (1999) 429-435

[14] D. S. Rajawat, S. Srivastava, S. P. Satsangee, International Journal of Electrochemical Science 7 (1) (2012) 11456-11469

[15] R. D. Riso, M. Waeles, P. Monbet, C. J. Chaumery, Analytica Chimica Acta 410 (1) (2000) 97105

[16] L. R. Popescu, E. M. Ungureanu, G. O. Buica, C. Dinu, M. Iordache, Scientific BulletinUniversity Politehnica of Bucharest Series B 75(4) (2013) 1454-2331

[17] F. Wang, J. Liu, Y. J. Wu, Y. M. Gao, X.F. Huang, Journal of the Chinese Chemical Society 56 (4) (2009) 778-784

[18] C. M. V. B. Almeida, B.F. Giannettio, Electrochemistry Communications 4 (1) (2002) 985-988

[19] B. K. Jena, C. R. Raj, Analytical Chemistry 80 (13) (2008) 4836-4844

[20] E. Bakker, M. Telting-Diaz, Analytical Chemistry 74 (1) (2002) 2781-2800

[21] L. Pujol, D. Evrard, K. Groenen-Serrano, M. Freyssinier, A. Ruffien-Cizsak, P. Gross, Frontiers in Chemistry 2 (19) (2014) 1-24

[22] Y. M. Sin, W. F. Teh, M. K. Wong, P. K. Reddy, Bulletin of Environmental Contamination and Toxicology 44 (1) (1990) 616-622 
[23] D. M. Gordin, T. Gloriant, G. Nemtoi, R. Chelariu, N. Aelenei, A. Guillou, D. Ansel, Materials letters 59 (23) (2005) 2936-2941

[24] D. Mareci, C. Bocanu, G. Nemtoi, D. Aelenei, Journal of the Serbian Chemical Society. 70 (6) (2005) 891-897

[25] G. Nemtoi, A. Ciomaga, T. Lupascu, Revue Roumaine de Chimie 57 (9-10) (2012) 837-841

[26] A. V. Sandu, A. Ciomaga, G. Nemtoi, C. Bejenariu, I. Sandu, Microscopy Research and Technique 75(12) ( 2012) 1711-1716

[27] G. Nemtoi, H. Chiriac, O. Dragoş, M.O. Apostu, D. Lutic, Acta Chemica lasi 17 (2) (2009) 151168

[28] G. Nemtoi, M. S. Secula, I. Cretescu, S. Petrescu, Revue Roumaine de Chimie 58 (12) (2007) 655-659

[29] G. Nemtoi, D.I. Cuciurean, Revista de Chimie 53 (2) (2002) 146-149

[30] S. I. M. Zayed, H. A. M. Arida, International Journal of Electrochemical Science 8 (2013) $1340-1348$

[31] J. Zima, I. Svancara, J. Barek, K. Vytras, Critical Reviews in Analytical Chemistry 39 (2009) 204-227

(C) 2014 by the authors; licensee IAPC, Zagreb, Croatia. This article is an open-access article distributed under the terms and conditions of the Creative Commons Attribution license (http://creativecommons.org/licenses/by/4.0/) 